ORIGINAL ARTICLE

\title{
Excessive exposure of sick neonates to sound during transport
}

\author{
L Buckland, N Austin, A Jackson, T Inder
}

Arch Dis Child Fetal Neonatal Ed 2003;88:F513-F516

See end of article for authors' affiliations ....................

Correspondence to: Dr Inder, 2nd Floor, Royal Children's Hospital Flemington Rd, Parkville, VIC 3052, Australia; inderł@cryptic.rch. unimelb.edu.au

Accepted 26 November 2002 ambulance, aircraft, and helicopter.

Design: Sound levels during 38 consecutive journeys from a regional level III neonatal intensive care unit were recorded using a calibrated data logging sound meter (Quest 2900). The meter was set to record " $A$ " weighted slow response integrated sound levels, which emulates the response of the human ear, and " $\mathrm{C}$ " weighted response sound levels as a measure of total sound level exposure for all frequencies. The information was downloaded to a computer using MS HyperTerminal. The resulting data were stored, and a graphical profile was generated for each journey using SigmaPlot software.

Setting: Eight journeys involved ambulance transport on country roads, 24 involved fixed wing aircraft, and four were by helicopter.

Main outcome measures: Relations between decibel levels and events or changes in transport mode were established by correlating the time logged on the sound meter with the standard transport documentation sheet.

Results: The highest sound levels were recorded during air transport. However, mean sound levels for all modes of transport exceeded the recommended levels for neonatal intensive care. The maximum sound levels recorded were extremely high at greater than $80 \mathrm{~dB}$ in the " $\mathrm{A}$ " weighted hearing range and greater than $120 \mathrm{~dB}$ in the total frequency range.

Conclusions: This study raises major concerns about the excessive exposure of the sick newborn to sound during transportation.

$\mathrm{S}$ ound levels have been monitored in neonatal intensive care units (NICUs) to develop international guidelines. ${ }^{1}$ Recommendations were made that they should not exceed $45-50 \mathrm{~dB}^{2}$ More recently, these recommendations have been extended to optimise developmental care for premature infants. ${ }^{3}$ The adverse effects of excessive sound levels on preterm behaviour have been noted ${ }^{5}$ and appear to be most pronounced in the sickest and smallest infants. ${ }^{78}$ The transportation of the sick newborn or premature infant should be viewed as an extension of the NICU environment, and, although international guidelines recommend that sound levels during transport do not exceed $60 \mathrm{~dB},{ }^{9}$ there is a paucity of data on sound level exposure in common modes of transport.

The aim of this study was to determine the level of exposure of sick infants to sound during transportation by a specialised neonatal transport team in ambulance, helicopter, and fixed wing aircraft.

\section{METHODS}

Subjects

Consecutive neonatal transportations from a regional level III NICU in Christchurch, New Zealand from March 2000 to January 2001 were selected. These included interhospital transfer of term and premature newborn infants, transport for investigations, and return of stable infants to their referring area hospital. A detailed record of all events during the journey was kept to allow correlation with sound levels. The data recorded included the times of arrival and departure, events requiring intervention for the infant, problems en route, and the type of transport. All three transport incubators used in the study had identical specifications (Airshields TI 500 models). The fixed wing aircraft used for all flights was a Cessna Golden Eagle 421, and the helicopter was a Eurocopter BK-117.

\section{Sound level recording device}

A calibrated data logging sound meter Quest 2900 (Quest Technologies, Oconomowoc, Wisconsin, USA) with a standard 0.5 inch prepolarised condenser microphone was used to record the sound levels. The measurement range was 20$140 \mathrm{~dB}$ with frequency range from $10 \mathrm{~Hz}$ to $20 \mathrm{KHz}$. The meter was set to record " $\mathrm{A}$ " weighted slow response integrated sound levels (LEQ), with a $3 \mathrm{~dB}$ exchange rate, and maximum levels (LMax). "A" weighted slow response is the international standard for assessing sound pressure levels, which emulates the response of the human ear. It is used to assess industrial sound measurements, as they reflect sound level exposure in the hearing range. " $\mathrm{C}$ " weighted response sound levels were also recorded as a measure of total sound level exposure for all frequencies, including those outside the range of the human ear. Each transport study produced a time weighted average automatically analysed over one minute epochs during transport. At the end of the journey, the results were also subdivided into transport modes.

\section{Recording device placement}

The meter was placed inside the incubator secured to the bar running parallel with the length of the mattress to which the safety straps were located. This was on the non-opening side of the incubator away from the main portholes. It was wrapped in dense, vibration absorbing, sorbo-rubber material $0.4 \mathrm{~cm}$ thick and then in disposable thin plastic to simulate the smoothness of the incubator wall. This also protected against fluid spill and/or infection contamination and was disposable. The end of the microphone was covered by the 
manufacturer's wind shield. This was retained as a safety measure to prevent injury to the infant if the sound meter became dislodged from the fixture during turbulence or sudden movement of the incubator. The placement of the microphone was approximately $10(0.5) \mathrm{cm}$ from the infant's ear. The variation in distance was due mainly to difference in head size and positioning of the baby in the incubator. The meter was activated when the transport team left the base hospital and not touched until after the baby had been removed. Therefore at no time was the transport team distracted from caring for the infant.

\section{Sound level analysis}

The information stored by the meter was downloaded to a computer using MS HyperTerminal. The data were stored, and a graphical representative profile was generated for each journey using SigmaPlot software. The relation between decibel levels and events or changes in transport mode was established by correlating the time logged on the sound meter with the standard transport documentation sheet. Statistical analysis for the comparison of sound levels in the different transport modes was by Student's $t$ test or one way analysis of variance for normally distributed data.

\section{RESULTS}

Thirty eight transportations were analysed. Eight included periods of country road ambulance transport lasting more than 30 minutes. Twenty four involved fixed wing aircraft. Four were by helicopter.

\section{Reason for transport}

Twenty of the transportations involved the retrieval of sick newborn infants from regional hospitals; these infants were predominantly prematurely born. Some $15 \%$ of the transportations were transfers of sick infants between hospitals for specialist investigations or treatment, with these infants being predominantly term born. Twelve were transfers of stable premature or term infants back to level II units.
Table 1 Sound levels $(\mathrm{dB})$ recorded in various modes of transport

\begin{tabular}{llll}
\hline Transport mode & LEQ & LMax & Peak "C" \\
\hline Ambulance, country $(n=8)$ & $74.1(0.7)$ & $77.2(0.9)$ & $115.4(4.5)$ \\
Ambulance, town $(n=38)$ & $64.9(1.9)$ & $72.5(3.4)$ & $109.4(6.3)$ \\
Fixed wing $(n=24)$ & $80.9(0.9)$ & $83.3(2.3)$ & $107.9(6.9)$ \\
Helicopter $(n=4)$ & $82.2(0.9)$ & $84.1(2.10$ & $121(0.4)$ \\
\hline
\end{tabular}

Values are mean (SD).

$L E Q$, " $A$ " weighted, sound range of the human ear; $L M a x$, maximum level for the " $A$ " weighted sound range of the human ear; Peak " $C$ ", sound levels representing all frequency sound level exposure.

\section{Sound levels}

The maximum sound levels were recorded during air transport (table 1). The maximum levels recorded were extremely high at greater than $80 \mathrm{~dB}$ in the " $\mathrm{A}$ " weighted hearing range and greater than $120 \mathrm{~dB}$ in the total frequency range.

\section{Ambulance trips}

There were 38 ambulance trip recordings in the city region, and eight of these had an additional period of country road transport. The mean sound levels (LEQ median "A" weighted levels, LMax " $\mathrm{A}$ ", and Peak " $\mathrm{C}$ " levels) were all significantly higher on country roads than on city roads (table $1 ; \mathrm{p}<0.01$ all values) Thus, there was a significant effect of the rougher country roads.

\section{Air transport}

The sound levels in fixed wing aircraft and helicopter were both significantly higher than in an ambulance (table 1; $\mathrm{p}<0.01$ all measures). There was no significant difference between the noise exposure between helicopter and fixed wing aircraft for any of the sound level measures (table l; $\mathrm{p}>0.1$ all values). Figures 1 and 2 show the changes in exposure during transport by ambulance and aircraft.

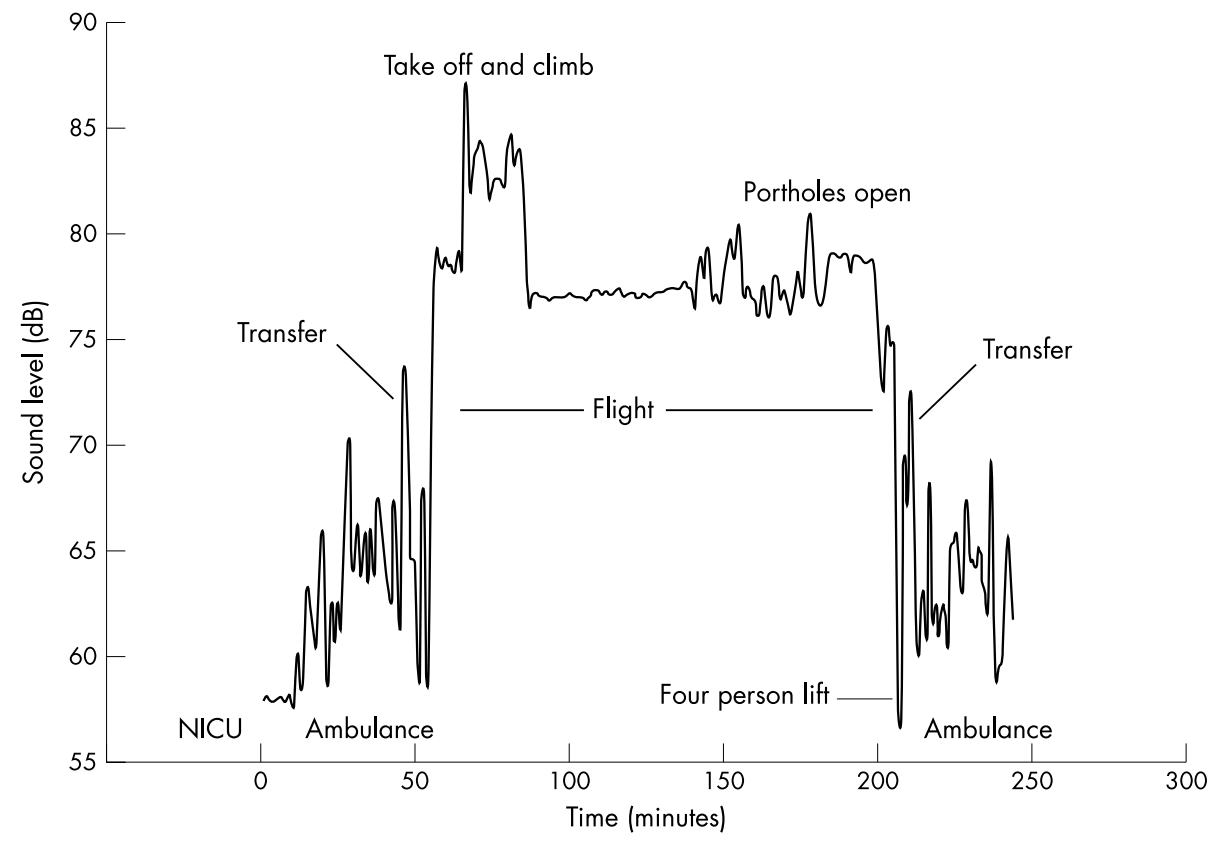

Figure 1 Transport of a non-ventilated infant to a specialised cardiac unit in Auckland, New Zealand from Christchurch Womens Hospital, lasting 240 minutes. Note the increased noise exposure during take off and when the portholes of the incubator were opened, and the variation in ambulance noise levels due to acceleration, speed, and road surface. Also note that all recordings are above the recommended level of $60 \mathrm{~dB}$. NICU, Neonatal intensive care unit. 


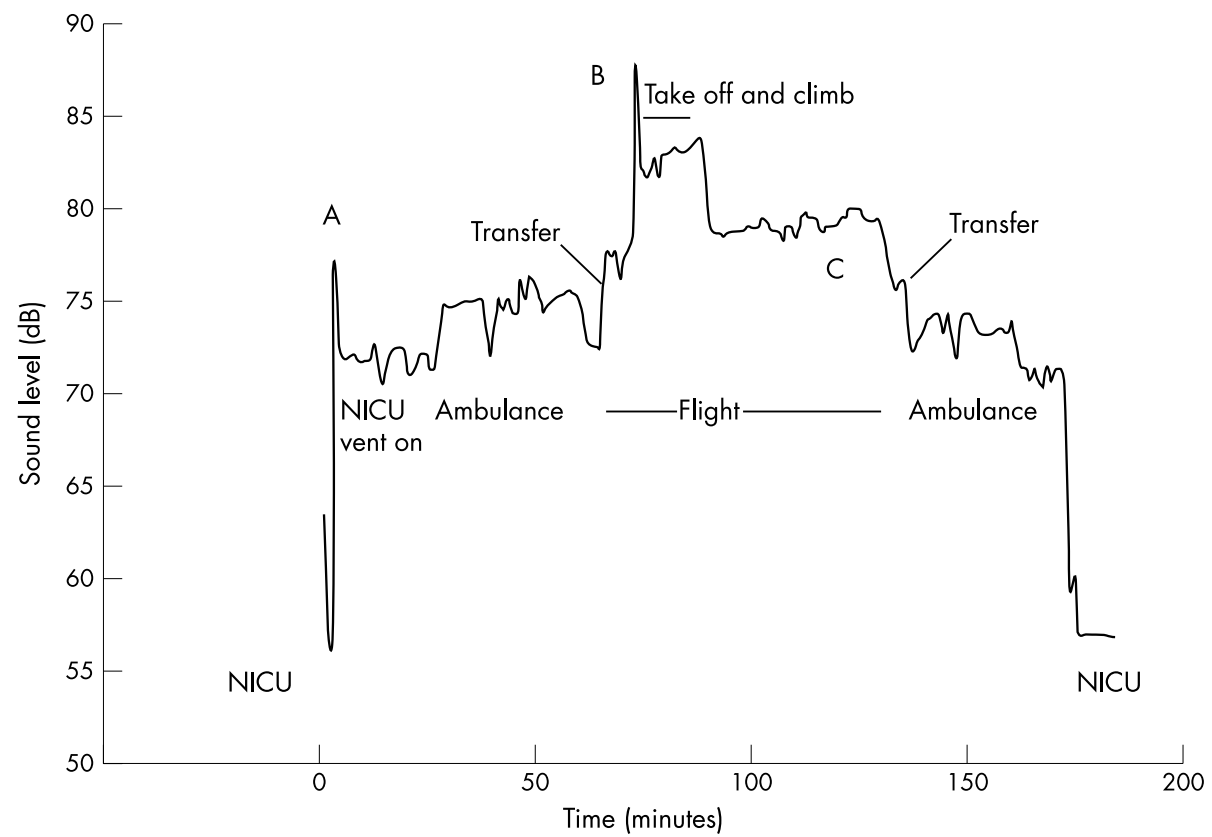

Figure 2 Transport of ventilated infant by ambulance and air over 180 minutes. Note: (A) the impact of the internal air compressor used to drive the ventilator, which raises sound levels above $70 \mathrm{~dB}$ before the start of transport; (B) the highest sound level recorded was on aircraft take off; (C) the high (close to $80 \mathrm{~dB}$ ) continuous level of exposure for more than an hour. NICU, Neonatal intensive care unit.

It is notable that there are brief, extremely high noise levels during take off (figs 1 and 2), when the portholes of the incubator are opened (fig 1), and when the internal air compressor used for the ventilator in the transport incubator is started (fig 2).

\section{DISCUSSION}

This study clearly documents that sick and premature infants are exposed to high levels of sound during all modes of standard neonatal transportation. The highest exposure occurred with aircraft transport, but all modes exceeded current recommended levels. ${ }^{2}{ }^{9}$ The higher levels of noise recorded in ambulances on country roads may be due to both the road surface and increased speed, both of which increase road noise.

There are few guidelines for acceptable sound levels during the transport of critically ill neonates. ${ }^{10}{ }^{11} \mathrm{McNab}^{9}$ recommended that, during paediatric and neonatal transportation, they should not exceed $60 \mathrm{~dB}$, recognising that excessive and unusual sound levels may occur during transport and thus allowing a higher exposure than that recommended for the NICU. This rationale to make a higher sound level acceptable during transport of a sick vulnerable newborn infant may be flawed, as these infants may indeed be much more sensitive to these auditory stimuli than the infant in hospital. However, our study clearly shows that nearly all sound levels recorded within the human hearing range during neonatal transport significantly exceeded these more lenient guidelines.

The transport crew in a small aircraft all wear hearing protection. ${ }^{12}$ Personal commercial hearing protection for adult passenger use produces a reduction of $21-28 \mathrm{~dB}$. Commercially available ear protection for neonates in neonatal units attenuates sound by only $7 \mathrm{~dB}$, which is insufficient for the level of exposure found in our study.

Sound and vibration are recognised trauma encountered in aviation medicine, ${ }^{13}$ causing fatigue, increased oxygen requirement, stress, and disorientation in adults. Noise during neonatal transport is acknowledged to be a problem too, but the prime concern expressed seems to be the difficulty of communication between personnel ${ }^{12}$ to further the care of the infant, not the effect on the physiological state of the infant. ${ }^{14}$ In contrast, the effect of sound stress in the NICU is internationally acknowledged. ${ }^{2}{ }^{15} 16$

Some infants may be more vulnerable than others to sound levels during transportation. Exposure to sudden noise in infants with hypoxic ischaemic encephalopathy can be associated with desaturation. ${ }^{17}{ }^{18}$ In aviation physiology, episodes of hypoxic stress are additive in their effect on the compromised patient. ${ }^{19}$

This study raises major concerns about the excessive exposure of the sick newborn to noise during transportation. There is now clear recognition that we need to modify exposure of such infants to light and sound to give better immediate and long term outcomes. Such recognition has influenced modern NICU designs. ${ }^{16}$ The same principles should be applied to the critical period of transportation of the sick newborn. It would be advantageous for all organisations engaged in neonatal and paediatric transport to conduct a data logging survey to highlight sound attenuation requirements. Then sound reduction strategies for transport incubators, such as incubator covers, internal sound absorbing material, and more effective sound reducing ear protection, could be designed.

\section{Authors' affiliations}

L Buckland, N Austin, A Jackson, Neonatal Unit, Christchurch Women's Hospital, Christchurch, New Zealand

T Inder, Murdoch Children's Research Institute, Royal Children's Hospital, Melbourne Howard Florey Institute, University of Melbourne, Australia

\section{REFERENCES}

1 Magnavita V, Arslan E, Benini F. Noise exposure in the neonatal intensive care units. Acta Otorhinolarygol Ital 1994;14:489-501.

2 Statement AP. Noise: a hazard for the fetus and the newborn. Pediatrics 1997:100:724-7.

3 Philbin M. Some implications of early auditory development for the environment of hospitalised newborn infants. Neonatal Netw 1996;15:71-3.

4 Glass P. The vulnerable neonate and the neonatal intensive care environment. Neonatology: pathophysiology and management of the newborn, 4th ed. Philadelphia: Lippincott, 1994:84-7. 
5 Philbin $M$. The influence of auditory experience on the behaviour of preterm newborn. J Perinatol 2000;20:s77-87.

6 Long J, Lucey J, AGS P. Noise and hypoxemia in the intensive care nursery Pediatrics 1980;65:143-5.

7 Todd N. At risk populations for hearing impairments in infants and children Int J Pediatr Otorhinolaryngol 1994;29:11-21.

8 Borradori C, Fawler C, Buclin T, et al. Risk factors of sensorineural hearing loss in preterm infants. Biol Neonate 1997;11:1-10.

9 Macnab AEA. Vibration \& noise in pediatric emergency transport vehicles: a potential cause of morbidity? Aviat Space Environ Med 1995;66:212-19.

10 National Health and Medical Research Council, Australia. Guidelines for neonatal transport services. Canberra: National Health and Medical Research Council, Australia, 1991.

11 Australian and New Zealand College of Anaesthetists/Australasian College for Emergency Medicine. Minimum standards for the transport of the critically ill. Melbourne: Australian and New Zealand College of Anaesthetists/ Australasian College for Emergency Medicine, 2000.
12 Cable G. Noise vibration and communication in aeromedical operations: review. Avmedia 1996;16:23-8.

13 Ewing R. Aviation medicine and other human factors for pilots. Auckland: David Ling Publishing Ltd, 1995.

14 Miller C. The physiological effects of air transport on the neonate. Neonatal Netw 1994;13:7-9.

15 Zahr L, de Traversay J. Premature infant responses to noise reduction by earmuffs: effects on behavioural and physiologic measures. J Perinatol 1995; 15:448-55

16 White R, Newbold P. Reinventing the newborn ICU. Health Forum J 1995 Mar:30-3.

17 Ciesielski S, Kopka J, Kidawa B. Incubator noise \& vibration: possible iatrogenic influence on the neonate. Int J Pediatr Otorhinolargol 1980;1:309-16.

18 Gajendragadkar GEA. Mechanical vibration in neonatal transport: a randomized study of different mattresses. J Perinatol 2000;20:307-10.

19 Fisher P. Hypozia: flight surgeons guide. USAF School of Aerospace Medicine $1995 \cdot 2-32-2-42$

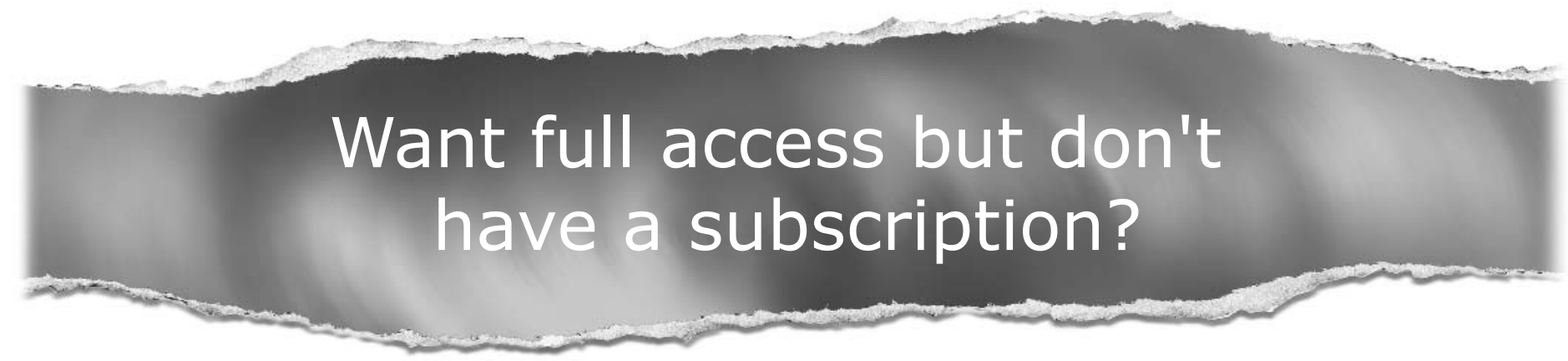

\section{Pay per access}

For just US $\$ 25$ you can have instant access to the whole website for 30 days. During this time you will be able to access the full text for all issues (including supplements) available. You will also be able to download and print any relevant pdf files for personal use, and take advantage of all the special features Archives of Disease in Childhood online has to offer. 